\title{
TURISMO E DIVISÃO TERRITORIAL DO TRABALHO NO POLO COSTA O SOL/RJ
}

\author{
Tourism and Territorial Division of Labor Pole in Costa do Sol/Rio de Janeiro
}

Maria Aparecida Pontes da Fonseca*

\begin{abstract}
Resumo
O objetivo do artigo é estabelecer uma relação entre a racionalidade encontrada no interior do espaço turístico constituído pelo Polo Costa do Sol e a natureza das intervenções manifestadas localmente pelo Programa de Regionalização do Turismo. Em nossa análise, partiremos do pressuposto de que internamente o referido espaço divide-se em áreas que desempenham funções distintas e complementares, gerando assimetrias espaciais, de modo que a área principal concentra os equipamentos da atividade turística, enquanto outras situadas no seu entorno abrigam os atrativos turísticos e desempenham o papel de áreas subsidiárias e complementares daquela que concentra os meios de produção. A análise se fundamentará na teoria do desenvolvimento desigual e combinado, que aponta as forças do mercado como responsáveis pelas desigualdades socioeconómicas encontradas no espaço. Nos procedimentos metodológicos adotados, foram utilizados dados da Relação Anual de Informações Sociais e do Centro de Informações de Dados do Rio de Janeiro, na obtenção de dados secundários, e realizadas entrevistas junto a algumas lideranças do setor turístico, vinculadas tanto ao setor público quanto ao privado.
\end{abstract}

Palavras-chave: Divisão Territorial do Trabalho, Programa de Regionalização do Turismo, Polo Costa do Sol/RJ/Brasil.

\begin{abstract}
The purpose of this article is to establish a relationship between the rationality found inside tourist area comprising the Pole of the Sun Coast and the nature of the interventions locally expressed by the Regionalization Program for Tourism. In our analysis on the assumption that internally the space is divided into areas that have distinct and complementary functions, generating spatial asymmetries, so the main focus of the tourism facilities, while others located in its surroundings are the attraction tour and play the role of subsidiary and additional areas that focus groups that means of production. The analysis is based on the theory of uneven and combined development, which shows the market forces as responsible for socioeconomic inequalities found in space. Methodological procedures adopted in data were used for the Annual Social Information and the Center for Information Data of Rio de Janeiro in obtaining secondary data and conducting interviews with some leaders of the tourism sector, linked to both the public sector, and the private sector
\end{abstract}

Key words:Territorial Division of Labor, Regionalization Program for Tourism, Pole of The Sun Coast/RJ.

\section{Résumé}

Cet article vise à établir une relation entre la rationalité que se trouve dans l'intérieur de l'espace touristique, constitué par la Costa do Sol, et la nature des interventions exprimées localement par le Programa de Regionalização do Turismo. Dans notre analyse, nous supposerons que l'espace intérieur est divisé en zones qui exercent des fonctions distinctes et complémentaires, qui génèrent des asymétries spatiales, de sorte que le domaine principal concentre la plupart des équipements de l'activité touristique, tandis que d'autres, situés dans ses environs, se trouvent les attractions touristiques qui jouent le rôle de zones subsidiaires et complémentaires de la région qui concentre les moyens de production. L'analyse sera basée sur la théorie du développement inégal et combiné, qui montre les forces du marché comme responsable des inégalités socio-économiques dans l'espace. Dans les procédures méthodologiques adoptées ont été utilisées les données de la Relação Anual de Informações Sociais, du Centro de Informações de Dados do Rio de Janeiro, pour l'obtention des données secondaires, et des entrevues avec certains dirigeants du secteur du tourisme, liés au secteur public et au secteur privé.

Mots-clés:Division Territoriale du Travail, Tourisme Programme de Régionalisation, Pôle Costa do Sol/ $\mathrm{RJ} /$ Brésil.

(*) Prof ${ }^{a}$. Dra . da Pós-Graduação em Geografia da Universidade Federal do Rio Grande do Norte - Av. Senador Salgado Filho, 3000, Lagoa Nova, CEP: 59078-970, Natal (RN) - Brasil, Tel: (+ 55 84) 3215-3569 / R: 2402 - mariapontes@ cchla.ufrn.br 


\section{INTRODUÇÃO}

O Programa de Regionalização do Turismo (PRT), instituído em 2004, se constitui atualmente em uma das principais políticas do Ministério do Turismo. Em sua formulação, a dimensão espacial assume relevância, primeiro porque ressalta as características intrínsecas ao território na elaboração do produto turístico, tendo em vista suas peculiaridades e diferenças; segundo porque concebe o território turístico de forma integrada e articulada, a partir de áreas regionalizadas em polos turísticos, cujo funcionamento ocorre a partir das interações espaciais entre os vários municípios que compõem os referidos polos.

Tendo em vista a valorização do território nessa política de intervenção, torna-se necessário analisar como o espaço turístico tem sido concebido e qual a lógica manifestada na sua produção, cuja diretriz é formulada pelas políticas de Estado.

Segundo Santos (1999), a produção do espaço geográfico expressa uma racionalidade imprimida pelas ações dos atores hegemônicos e que se manifesta materialmente na distribuição dos objetos ou ainda nas formas espaciais. Assim, algumas questões se colocam para os geógrafos e outros estudiosos do turismo, tais como: Qual é a lógica interna do espaço turístico ou, de outra forma, como se manifesta a divisão territorial do trabalho no interior de um espaço turístico? Como ocorrem as interações espaciais no interior desse espaço? Como as ações dos agentes hegemônicos (Estado e Mercado) se manifestam no espaço turistificado, dotando-o de uma racionalidade?

A partir de tais questionamentos, desenvolveremos o artigo com o objetivo de identificar a racionalidade que se manifesta na divisão territorial do trabalho verificada no interior do espaço turístico inserido no Polo Costa do Sol/RJ.

Em nossa análise, partiremos do pressuposto de que internamente o espaço divide-se em áreas que desempenham funções distintas e complementares, gerando assimetrias espaciais, de modo que a área principal concentra os meios de produção da atividade turística, isto é, a infraestrutura turística composta pelos meios de hospedagens - espinha dorsal da atividade -, mas também por restaurantes, agências de viagens e locadoras de automóveis; enquanto outras situadas no seu entorno encontram-se os atrativos turísticos e desempenham o papel de áreas subsidiárias e complementares daquela que concentra os meios de produção.

A estrutura espacial resultante desse processo mostra que a organização interna do espaço turístico é desigual e combinada, onde algumas áreas são mais beneficiadas do que outras, apesar de dialeticamente uma só existir em função da outra. Essa racionalidade que identificamos no referido espaço resulta das ações dos atores hegemônicos, conforme aponta Santos (1999), no caso, pelo mercado. No entanto, as ações do poder público vêm ratificar e estimular as assimetrias promovidas pelo funcionamento do mercado. Tal afirmação pode ser exemplificada pelo Programa de Regionalização do Turismo, que reforça a desigualdade já existente no interior do espaço turístico, ao eleger os municípios com melhor infraestrutura turística como indutores do desenvolvimento turístico dos polos identificados por esse Programa.

Desta forma, a análise se fundamentará na teoria do desenvolvimento desigual e combinado, que aponta as forças do mercado como responsáveis pelas desigualdades socioeconômicas encontradas no espaço. No entanto, é preciso reconhecer os limites teóricos desta abordagem, que em sua reformulação recente, reconhece que, além das forças do mercado, é necessário também considerar os elementos endógenos do território, para explicar as assimetrias espaciais verificadas em suas diversas escalas de análise (MÉNDEZ, 1997).

Nos procedimentos metodológicos adotados, foram realizadas entrevistas junto a lideranças do setor turístico, vinculadas tanto ao setor público, como ao privado. Os dados secundários foram obtidos na Relação Anual de Informações Sociais (Rais/Mte) e no Centro de Informações de Dados do Rio de Janeiro (Cide/RJ). Apesar da área objeto do presente estudo referir-se ao Polo Costa do Sol, nos deteremos principalmente na análise dos três municípios turísticos mais relevantes: Arraial do Cabo, Armação de Búzios e Cabo Frio, conhecidos como ABC. 


\section{BREVE CARACTERIZAÇÃO DO POLO COSTA DO SOL}

Conforme aponta Boyer (2003), a partir do século passado as estrelas e astros de cinema passaram a assumir papel de difusores das destinações turísticas, uma vez que vêm sendo imitados por um número de pessoas cada vez maior. Este parece ter sido o caso de Armação de Búzios e seu entorno, que, por ocasião da visita de Brigitte Bardot, no início da década de sessenta (1964), se projetou para o mundo, desencadeando o processo de turistificação da localidade. Até hoje a atriz se constitui num ícone da destinação.

Desde o início da década de cinquenta, a região era frequentada por uma seleta elite carioca, para fins de veraneio, concentrando-se em uma pequena vila de pescadores, atual município de Armação de Búzios (FONSECA et al., 2001). Posteriormente, os argentinos começaram a chegar, construir residências e alugar quartos, até transformar suas próprias residências em pequenas pousadas. No entanto, foi a partir dos anos setenta, com a construção da Ponte Rio-Niterói em 1977, que ocorreu o boom turístico na região devido à facilidade de acesso que esta proporcionou, ocasionando também grande proliferação de segundas residências.

A visita de B. Bardot e a construção da referida ponte foram, portanto, dois fatos que contribuíram para a difusão do turismo no Polo, sendo que Armação de Búzios assumiu localmente uma maior relevância turística. Na Figura 1, podemos observar a evolução recente dos estabelecimentos hoteleiros do Polo e a liderança incontestável desse município.
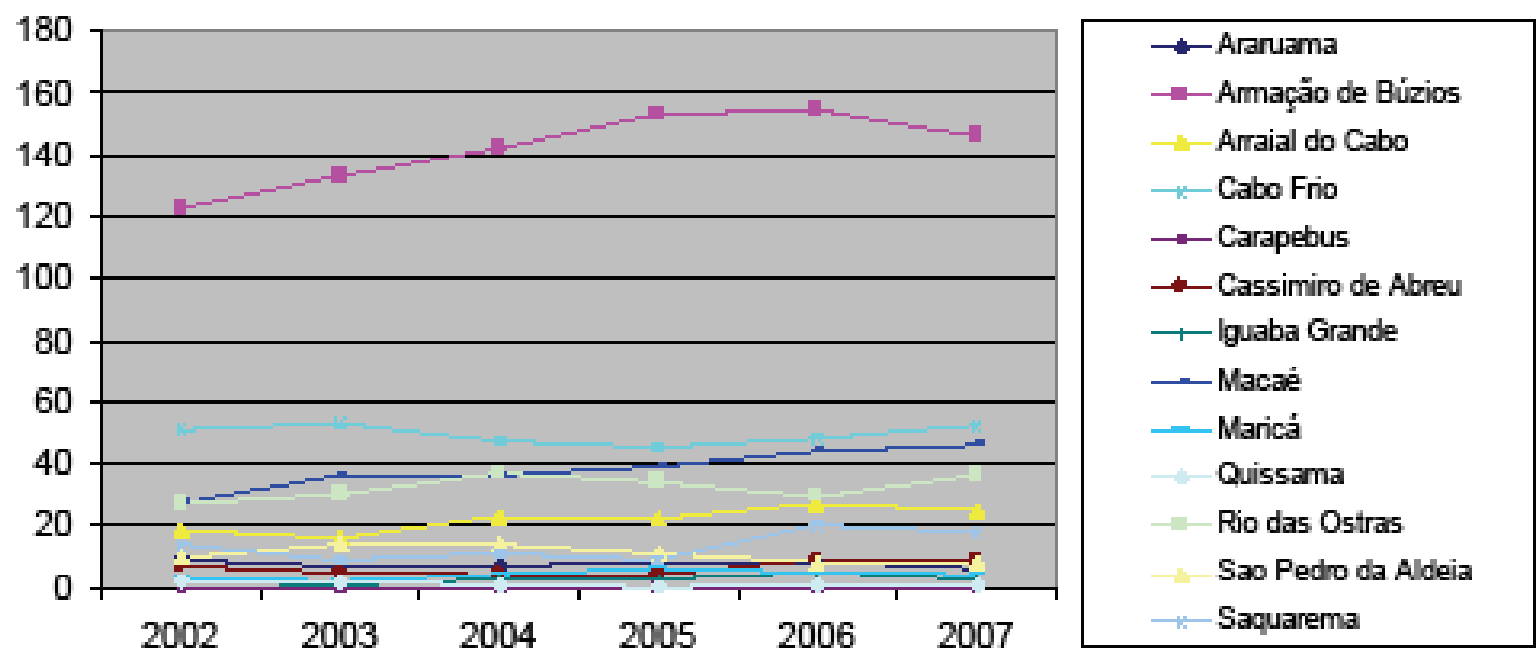

Figura 1 - Gráfico de evolução dos estabelecimentos hoteleiros no Polo Costa do Sol/RJ - 2002/2007 Fonte: Rais, 2007

O referido Polo turístico apresenta elevado índice de diversidade de atrativos turísticos, equiparando-se com a Região Metropolitana do Rio de Janeiro, ambos com pontuação 6 - a mais elevada -, conforme classificação elaborada pela Secretaria de Estado de Planejamento, Desenvolvimento Econômico e Turismo, juntamente com a Companhia de Turismo do Estado do Rio de Janeiro (Sepdet/Turisrio, 2001), sendo que, dos quinze municípios melhor posicionados no Estado, cinco pertencem a esse Polo: Cabo Frio $\left(5^{\circ}\right)$ Arraial do Cabo $\left(9^{\circ}\right)$, Armação de Búzios $\left(10^{\circ}\right)$, Araruama $\left(11^{\circ}\right)$ e Rio das Ostras $\left(12^{\circ}\right)$.

Os principais atrativos da destinação estão ligados ao segmento sol-praia, ressaltando-se as atividades de mergulho, esportes náuticos, passeio de barcos, dentre outros. Destacam-se ainda várias lagoas, tais como de Maricá, Saquarema e Araruama, e atrativos culturais constituídos de alto valor histórico e arquitetônico, testemunho do período colonial. 
Possui alto índice de insolação anual e curtos períodos de chuva durante o ano. Assim, as características do espaço regional fazem com que o mesmo se apresente como um fator de produção para a atividade turística, conforme aponta Sanchéz (1991), de modo que todos esses aspectos evidenciam o alto potencial turístico da região.

O Polo Costa do Sol , anteriormente denominado Região dos Lagos, se constitui em um dos mais importantes polos de atração turística do Estado fluminense, abrangendo 10,3\% do número de pessoal empregado em hotéis e similares e $22,5 \%$ dos meios de hospedagens existentes do total estadual, no ano de 2007 (Rais), que se caracterizam pelo predomínio de pousadas e pequenos estabelecimentos hoteleiros.

Outros indicadores mostram ainda a participação dessa região turística em relação ao Estado: $26,21 \%$ do total de visitantes, $33,16 \%$ do total de veranistas e $8,90 \%$ do total de turistas. Dentre os visitantes, $90,45 \%$ correspondem aos veranistas, enquanto $9,55 \%$ correspondem aos turistas, constituindo-se, portanto, em importante polo de veraneio, o que ocasiona problemas de grande magnitude nos períodos de feriados prolongados e no verão, devido à sobrecarga de infraestrutura básica, que já é bastante precária. (SEPDET/TURISRIO, 2001).

Sua demanda é constituída por turistas nacionais procedentes dos Estados do Rio de Janeiro, São Paulo, Minas Gerais e Espírito Santo; e internacionais, dentre os quais se destacam os originários da Argentina, que representam cerca de $70 \%$ dos turistas estrangeiros. Mas a localidade também é visitada por turistas de outras nacionalidades, tais como italianos, portugueses, americanos, franceses, chilenos e peruanos, conforme informações obtidas no trabalho de campo. A participação do número de turistas estrangeiros é mais elevada no período da baixa estação.

\section{A DIVISÃO TERRITORIAL DO TRABALHO NO INTERIOR DA ÁREA TURÍSTICA CONSTITUÍDA PELO POLO COSTA DO SOL}

A presente análise se fundamenta na teoria do desenvolvimento desigual e combinado, que destaca as forças do mercado como a principal responsável pela geração de desigualdades encontradas no espaço geográfico (SMITH,1988).

Harvey $(2004$, p.98) reafirma que as desigualdades e diferenciações espaciais são fundamentais para a própria reprodução do capitalismo, especialmente no contexto da globalização, sugerindo inclusive uma "mudança de linguagem, de globalização para desenvolvimento geográfico desigual".

Em sua formulação recente, embora os elementos internos ao território, tal como enfatizado pela teoria do desenvolvimento endógeno (cultura, disponibilidade de capitais, disponibilidades de recursos humanos, organização institucional, dentre outros), também sejam considerados na explicação dos fatores responsáveis pela geração de assimetrias espaciais, as forças do mercado assumem papel preponderante nessa explicação (MÉNDEZ,1997).

Ao discutir a lógica do desenvolvimento desigual desencadeada pelo processo de reprodução do capital, Smith (1988, p.19) observa o que de fato o capital realiza é

a produção do espaço na sua própria imagem e a exploração dessa idéia levará a uma mais completa integração do espaço e da sociedade na teoria do desenvolvimento desigual. Pois o capital não somente produz o espaço em geral, mas também produz as reais escalas espaciais que dão ao desenvolvimento desigual a sua coerência.

Dessa forma, o desenvolvimento desigual pode ser identificado nas diversas escalas espaciais (regional, nacional e global) como um processo decorrente das forças do mercado. Nos estudos desenvolvidos por Samir Amin na segunda metade do século XX, o autor destacou a dimensão polarizadora do capitalismo, observando que esse sistema econômico é constituído de dois polos: 
um centro e diversas periferias $(B E N K O, 1999)$. Ou seja, a constituição de áreas centrais é fundamental para a realização do capital.

A perspectiva teórica delineada acima nos possibilita compreender a estruturação da atividade turística na região turística compreendida pelo Polo Costa do Sol, onde um município polariza a atividade (Armação de Búzios), enquanto outros desempenham papel secundário e complementar.

Este município pertencia anteriormente a Cabo Frio, mas o desenvolvimento turístico e o crescimento populacional do município foi tal que, no ano de 1997, ocorreu sua emancipação política.

O desenvolvimento inicial da atividade foi espontâneo e as condições endógenas locais mais propicias possibilitaram sua expansão, de modo que esse município foi assumindo a liderança e centralidade no turismo regional, convertendo-se no principal espaço produtivo, onde se concentram os equipamentos e a infraestrutura turística (ver Gráfico 1). O município assume, portanto, conforme Sánchez (1991), o papel econômico como meio de produção direto.

Os treze municípios que compõem o Polo se diferenciam no que se refere à sua importância turística no contexto regional, bem como às funções que exercem para o funcionamento da atividade. O município de Macaé, por exemplo, se destaca na dotação de infraestrura básica e hoteleira, embora sua dinâmica não advenha da atividade turística e sim da petrolífera, desenvolvida na Bacia de Campos. Por isso, não nos deteremos na análise desse município.

No conjunto, existem três municípios que assumem relevância turística: Arraial do Cabo, Armação de Búzios e Cabo Frio. Estes englobam 63\% dos estabelecimentos hoteleiros e 62,5\% dos empregados em hotéis e similares existentes no Polo (ver Figuras 2 e 3). Tais municípios possuem uma unidade fisiográfica, complementam-se e exercem papéis diferenciados para o funcionamento do turismo regional, sendo neles que vamos nos deter na análise.
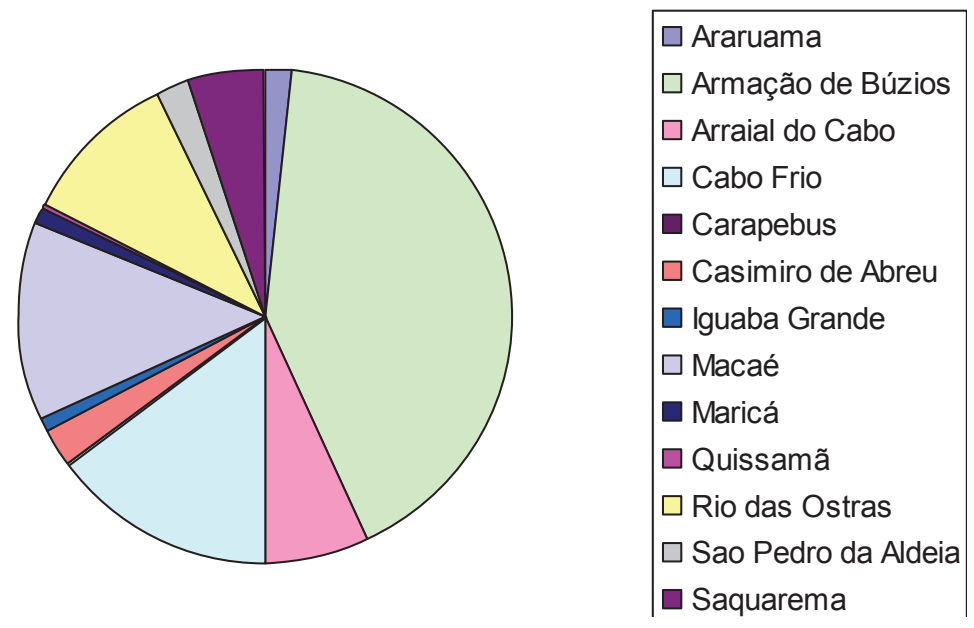

Figura 2 - Gráfico dos estabelecimentos hoteleiros no Polo Costa do Sol / RJ - 2007 Fonte: Rais, 2007.

Armação de Búzios assume o papel central da atividade turística do polo, utilizando-se dos recursos existentes nos demais municípios (atrativos turísticos e infraestutura básica) para promover e expandir sua atividade turística, que se constitui na única atividade econômica do município. Sua economia, portanto, se resume na atividade turística. 


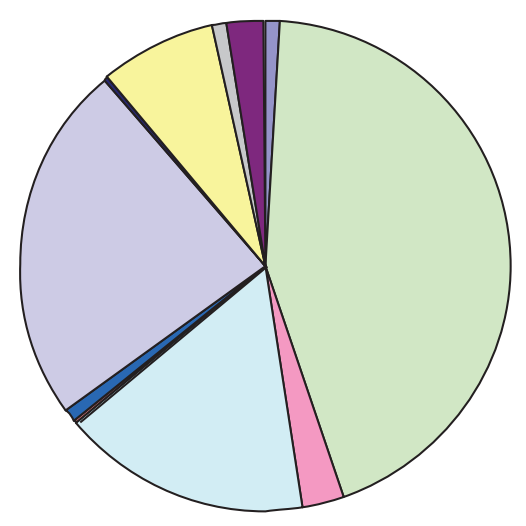

\begin{tabular}{|l|}
\hline$\square$ Araruama \\
$\square$ Armação de Búzios \\
$\square$ Arraial do Cabo \\
$\square$ Cabo Frio \\
$\square$ Carapebus \\
$\square$ Casimiro de Abreu \\
$\square$ lguaba Grande \\
$\square$ Macaé \\
$\square$ Maricá \\
$\square$ Quissamã \\
$\square$ Rio das Ostras \\
$\square$ Sao Pedro da Aldeia \\
$\square$ Saquarema
\end{tabular}

Figura 3 - Gráfico do número de empregados em hotéis e similares no Polo Costa do Sol / RJ - 2007 Fonte: Rais, 2007

A seguir, veremos como os três municípios, objeto de nossa análise, se complementam para a realização da atividade turística. Para tanto, selecionamos algumas variáveis para análise, isto é, a infraestrutura turística, da qual destacamos os meios de hospedagens, que se constituem o elemento estruturante da atividade; a acessibilidade e a formação de recursos humanos; além dos atrativos turísticos.

\section{A infraestrutura turística}

Armação de Búzios concentra 41\% dos estabelecimentos hoteleiros do pólo, enquanto Cabo Frio engloba 14,7\% e Arraial do Cabo apenas 7\% (RAIS, 2007). Além de se destacar regionalmente, Búzios ocupava em 2005 a segunda colocação em relação aos demais municípios do Estado, tanto no número de estabelecimentos hoteleiros (170), quanto no de empregados em estabelecimentos hoteleiros (1.494), abaixo apenas da cidade do Rio de Janeiro, com 464 e 15.285, respectivamente (Cide).

Este município oscila entre a sexta ou sétima posição enquanto destino internacional do país, mas, quando saímos dos grandes centros urbanos e consideramos as cidades médias, os balneários, ele passa a se constituir no destino internacional do Brasil que mais recebe turistas estrangeiros. Essa localidade também se diferencia por ter praias diversificadas, gastronomia de padrão internacional e vida noturna agitada, sendo frequentada por personalidades. Sua imagem está associada a luxo, charme e glamour.

\section{A acessibilidade e a formação de recursos humanos}

Cabo Frio exerce um papel fundamental no fornecimento de serviços básico para seu entorno, uma vez que é um polo administrativo regional. No que se refere à atividade turística, destacaremos dois tipos de serviços particularmente importantes oferecidos pelo município: o aeroporto e as instituições responsáveis pela formação de mão de obra.

A acessibilidade dos turistas nacionais à região ocorre pela vias rodoviárias, enquanto a internacional ocorre, principalmente, pela via aérea. As principais vias que dão acesso à destinação turística são: BR - 101, RJ - 106, RJ - 124, RJ - 142. Verifica-se a existência de cinco aeroportos: um em Macaé (administração da Infraero), um em Cabo Frio, Maricá e Saquarema (administração estadual e municipal) e um em Armação de Búzios (vinculado a um empreendimento turístico). É importante ressaltar a relevância do aeroporto de Cabo Frio para a acessibilidade turística, uma 
vez que este é utilizado pelos voos charters que transportam, dentre outros, os turistas argentinos para Armação de Búzios.

Com relação aos centros de formação de recursos humanos para o segmento turístico devemos destacar também o papel de Cabo Frio, que contém três instituições de ensino superior, oferecendo cursos de graduação, e uma de ensino médio, todas relacionadas ao setor turístico: a Universidade Veiga de Almeida, a Universidade Estácio de Sá, a Universidade Federal Fluminense e uma Escola Técnica Federal.

A infraestrutura básica do Polo Costa do Sol possui, porém, um dos piores indicadores do Estado fluminense com relação à coleta de lixo, esgotamento sanitário e abastecimento de água potável, o que se constitui num grave problema para a competitividade turística da região, uma vez que a qualidade ambiental é um requisito fundamental para o êxito de uma destinação turística internacional, conforme os padrões atuais exigidos pelo mercado.

\section{Atrativos turísticos}

Apesar de seus inegáveis atrativos turísticos, naturais e criados, Armação de Búzios necessita dos demais municípios para funcionar satisfatoriamente e manter os turistas por mais tempo ou ainda aumentar a taxa de permanência do visitante. Necessita, inclusive, explorar os atrativos turísticos de outras localidades, levando seus visitantes para apreciar os atrativos de Arraial do Cabo e de Cabo Frio.

Conforme pesquisa realizada pela Sepdet/Turisrio (2001), os atrativos turísticos com poder de atração de demanda internacional, se distribuem da seguinte forma: Armação de Búzios apresenta seis atrativos turísticos naturais e um cultural, Cabo Frio apresenta três atrativos turísticos naturais e sete culturais, e Arraial do Cabo um atrativo turístico natural e um cultural.

Já os atrativos turísticos com poder de atração de fluxos turísticos nacionais, estes se distribuem da seguinte forma: Armação de Búzios apresenta oito atrativos naturais e nenhum cultural, Cabo Frio apresenta cinco naturais e seis culturais, e Arraial do Cabo, seis naturais e sete culturais (ver Quadro 1).

Através desses dados, podemos observar que, embora Armação de Búzios possua muitos atrativos turísticos naturais, seus atrativos culturais são restritos, limitando-se a um, revelando, portanto, que são pouco diversificados. Já Cabo Frio apresenta uma variedade de atrativos, ressaltando-se os culturais, inclusive com poder de atração de demanda internacional. Arraial do Cabo também apresenta uma maior variedade de atrativos turísticos, com destaque para os culturais, também com poder de atração de turistas nacionais. Este último município apresenta, além do mais, unidades de conservação de grande valor turístico, tais como: Dunas de Cabo Frio, Área de Preservação Ambiental da Massambaba, Reserva Ecológica da Massambaba (essas três sob a tutela do Estado do Rio de Janeiro); e a Reserva Extrativista Marinha de Arraial do Cabo (sob a tutela da União). Cabo Frio possui uma Unidade de Conservação - a Dunas de Cabo Frio -, enquanto Armação de Búzios não possui qualquer área que se enquadre nessa classificação.

Quadro 1 -Atrativos turísticos dos municípios selecionados no Polo Costa do Sol / RJ

\begin{tabular}{|l|c|c|c|c|}
\hline \multirow{2}{*}{ MUNICÍPIOS } & \multicolumn{2}{c|}{ Internacional } & \multicolumn{2}{c|}{ Nacional } \\
\cline { 2 - 5 } & Naturais & Culturais & Naturais & Culturais \\
\hline Armação de Búzios & 6 & 1 & 8 & 0 \\
\hline Cabo Frio & 3 & 7 & 5 & 6 \\
\hline Arraial do Cabo & 1 & 1 & 6 & 7 \\
\hline
\end{tabular}

Fonte: Sepdet/Turisrio (2001)

Com esses dados, queremos mostrar que o principal município turístico do Polo - Armação de Búzios -, necessita dos atrativos turísticos localizados nos dois outros municípios para poder 
oferecer um produto turístico mais diversificado, não se limitando ao binômio sol-praia. Os atrativos culturais, testemunhos da história da região, que fazem parte de seu produto turístico, pertencem a Cabo Frio e Arraial do Cabo. Inclusive porque, quando chove, torna-se necessário oferecer outras opções para os visitantes.

Os três municípios, no entanto, se complementam turisticamente e cada um exerce papéis distintos para o funcionamento da atividade turística. Armação de Búzios concentra os meios de produção e os empregos gerados pela atividade (ver Figura 4), enquanto Cabo Frio participa oferecendo atrativos turísticos (naturais e culturais), infraestrutura, serviços básicos e instituições de capacitação de mão de obra. Já Arraial do Cabo participa do turismo regional basicamente como local de visitação turística, por possuir vários atrativos turísticos naturais.

As interações espaciais resultantes no interior desse espaço ocorrem de modo a concentrar a riqueza gerada pelo turismo no município polarizador da atividade, isto é, em Armação de Búzios, enquanto cabe aos demais dar sustentação à principal atividade econômica desse município. Particularmente, no caso de Arraial do Cabo, a atividade tem se mostrado bastante conflituosa, gerando inclusive desentendimentos, em função dos impactos negativos gerados localmente, particularmente com os pescadores, já que os passeios náuticos e as atividades de mergulho são os principais atrativos para os visitantes.

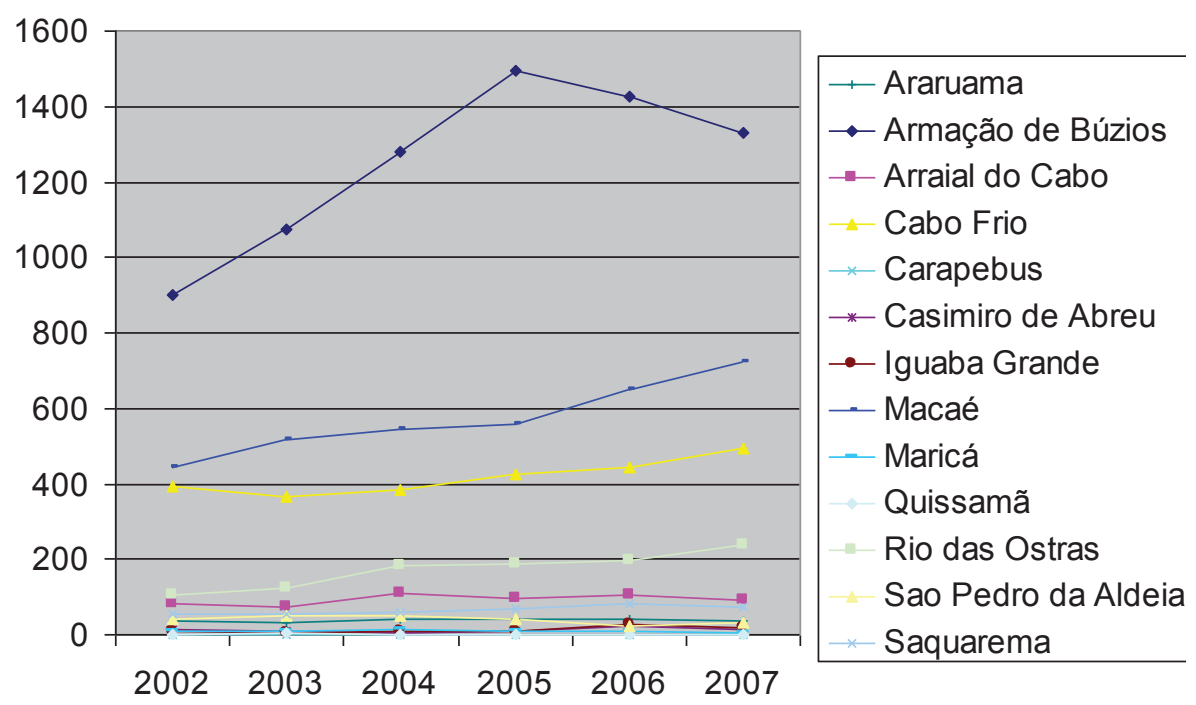

Figura 4 - Gráfico de evolução do número de empregados em hotéis e similares no Polo Costa do Sol/RJ - 2002/2007

Fonte: Rais, 2007

\section{O PROGRAMA DE REGIONALIZAÇÃO DO TURISMO}

No primeiro mandato do governo de Luiz Inácio Lula da Silva (2003-2006), foi criado o Ministério do Turismo (MTur) e uma das políticas idealizadas que assumiu importância, sendo inclusive priorizada na segunda gestão de seu governo, refere-se ao Programa de Regionalização do Turismo (PRT). Para os geógrafos, particularmente, este Programa governamental assume relevância uma vez que incide diretamente no espaço, considerando-se a seletividade das ações no que diz respeito às áreas prioritárias das ações e investimentos e à importância da dimensão espacial na operacionalização do Programa estruturado a partir da concepção de polos, conforme veremos adiante. 
Foram identificadas 200 regiões turísticas no Brasil e 3.819 municípios fazem parte do Programa. Nas palavras do ministro Walfrido dos Mares Guia, "o modelo de gestão adotado pelo MTur está voltado para o interior dos municípios do Brasil, para as suas riquezas ambientais, materiais e patrimoniais, e para suas populações, em contraponto aos prejuízos impostos pela modernização" (MTur, 2004, p. 8). Através da regionalização, esse Programa procura criar uma sinergia e desenvolver ações de parceria e cooperação entre os municípios do interior do país que apresentam potencialidades turísticas, segundo os documentos oficiais.

Desta forma, o Programa de Regionalização do Turismo pretende, entre outras coisas, interiorizar essa atividade, estruturando-a a partir dos polos turísticos identificados por todo o país (Brasil, 2004). Um de seus pontos centrais era a identificação dos municípios que pudessem desencadear o desenvolvimento do turismo regional, chamados "municípios indutores", de modo que, através destes, fosse possível estruturar as destinações para o turismo internacional.

Através do Conselho de Desenvolvimento do Turismo (CONDETUR), procurou-se, dentre outras atribuições pertinentes a esse órgão, identificar e viabilizar roteiros turísticos, de modo a integrar os municípios englobados no Polo, visando à promoção do desenvolvimento turístico regional.

Tal modelo parece ter sido inspirado na teoria dos polos de crescimento desenvolvida por François Perroux, nos anos sessenta do século XX, que apregoava a ideia de que, através de um centro regional, seria possível promover o desenvolvimento socioeconômico por toda a área polarizada em seu entorno, através da implantação de unidades industriais, o que, na prática, não se mostrou muito exitoso em algumas experiências empreendidas no final do século anterior.

Para Becker (1996), o Plano Nacional de Turismo (PLANTUR), instituído em 1992, já previa o desenvolvimento de polos turísticos integrados e se constituía no cerne da estratégia de diversificação e expansão do turismo para novas áreas do Brasil, uma vez que a infra-estrutura turística estava fortemente concentrada no Sul e Sudeste do país. Uma década depois, essa ideia é retomada e reformatada, constituindo-se em uma das principais políticas de turismo do atual governo.

No que se refere ao PRT, os objetivos são menos ambiciosos do que aqueles que se almejavam com a implantação dos polos de desenvolvimento, na medida em que a finalidade é a promoção do turismo regional, visando à preparação da destinação, agora concebida em termos de polo, para receber uma demanda turística internacionalizada, o que vai exigir uma adequação a um padrão de qualidade mais elevado.

No Rio de Janeiro foram identificados onze polos turísticos, a saber: Agulhas Negras, Metropolitano, Costa do Sol, Serra Verde Imperial, Costa Verde, Vale do Café, Baixada Fluminense, Serra Norte, Caminhos da Mata, Costa Doce e Noroeste das Águas.

No que se refere ao Polo Costa do Sol, a pesquisa identificou uma enorme distância entre a proposição dessa política pública e as condições objetivas verificadas internamente entre os municípios englobados pelo Polo para que sua implantação seja exitosa e atenda aos objetivos propostos no sentido de integrar turisticamente os municípios. É importante mencionar que esse Polo já se constitui numa destinação internacional, sendo que Armação de Búzios é bastante conhecida fora do país.

Primeiramente é necessário considerar que a atividade turística do Polo Costa do Sol vem passando por dificuldades. Observando os indicadores da Tabela 1 verifica-se que, a partir de 2006, começa a haver um declínio no número de estabelecimentos hoteleiros e similares nos municípios turísticos mais importantes e no seu entorno (Armação de Búzios, Arraial do Cabo, Araruama, Iguaba Grande, Maricá, Saquarema); enquanto outros permanecem estagnados (Cassimiro de Abreu, Quissama e São Pedro da Aldeia); apresentando um pequeno crescimento apenas os municípios de Cabo Frio, Macaé e Rio das Ostras. No conjunto do Polo verifica-se uma ligeira redução de 1,1\% do número de hotéis .

Mesmo considerando-se que o declínio possa ter ocorrido em função das mudanças na classificação efetuada pela RAIS no que se refere aos dados do setor hoteleiro a partir de 2006, e que 
tal fato possa ter influenciado esses indicadores, as entrevistas realizadas revelaram que a atividade turística regional é motivo de preocupação, especialmente pelo fato de os agentes turísticos dos municípios não se entenderem e não terem uma política articulada, decorrente da competitividade verificada entre eles. O resultado disto é que as ações de cada município terminam por ocorrer de forma isolada.

Outro fator que tem contribuído para a crise que se anuncia para o setor hoteleiro é a enorme proliferação de casas de veraneio, que também são utilizadas para a obtenção de renda extra pelos seus proprietários, causando problemas para os empresários locais, conforme manifestado por representantes do segmento empresarial tanto de Armação de Búzios como de Cabo Frio. Segundo depoimento de uma das lideranças de Armação de Búzios, verifica-se, inclusive, um dilema entre ser uma cidade turística ou uma cidade de veraneio.

Além da dificuldade de articulação, ocorre a insatisfação de alguns municípios que se sentem inseridos no turismo de forma marginal, como é o caso de Arraial do Cabo, que, embora se constitua num importante local de visitação de turistas para a realização de passeios náuticos, fica apenas com os efeitos residuais dos dividendos gerados pela atividade, além dos problemas ambientais e sociais mencionados acima.

Todos os agentes turísticos locais - públicos e privados - consideram que o PRT é importante e depositam uma enorme expectativa numa revitalização do turismo regional que hoje agoniza no meio de inúmeros problemas, inclusive o de identidade. Ressaltam esses agentes que o principal problema é de ordem política, devido às dificuldades de conciliar os interesses.

Visando buscar alternativas, o Conselho de Desenvolvimento do Turismo (CONDETUR) do Polo Costa do Sol foi estruturado e seu presidente está desenvolvendo ações no sentido de criar uma sinergia no Polo e promover maior integração. Uma das ações que está sendo desenvolvida é a criação de roteiros turísticos.

No que se refere à Armação de Búzios, o presidente do Conselho observa ... temos poucos atrativos, por isso a importância da regionalização. Ou seja, a lógica subjacente neste discurso é que o desempenho satisfatório do turismo buziano, numa perspectiva futura, depende da ampliação dos atrativos encontrados e que poderão ser implantados nos demais municípios englobados no PCS. Portanto, o que se pode concluir é que o PRT vem de encontro aos interesses do setor empresarial turístico de Armação de Búzios.

Já os agentes dos demais municípios consideram relevante o PRT, conforme manifestaram em suas falas, no entanto parecem um tanto céticos, pois observam que Armação de Búzios é o centro do turismo regional para onde é canalizada a riqueza gerada pela atividade, permanecendo os efeitos residuais e os impactos ambientais nos locais de visitação que dão sustentação à sua economia baseada no turismo. Por isto, esses agentes não se mobilizam muito para o êxito do Programa.

No intuito de promover a dinamização dos polos criados pelo Mtur, foram selecionados, em todas as unidades da federação brasileira, os municípios indutores do turismo, através dos quais seria promovido e operacionalizado o desenvolvimento do turismo regional. No Rio de Janeiro, por exemplo, foram selecionados cinco municípios indutores: Rio de Janeiro (Polo Metropolitano), Parati, Angra dos Reis (Polo Costa Verde), Petrópolis (Polo Serra Verde Imperial) Armação de Búzios (Polo Costa do Sol). 
Tabela 1 - Estabelecimentos hoteleiros e similares no Polo Costa do Sol / RJ - 2002/ 2007*

\begin{tabular}{l|c|c|c|c|c|c}
\hline MUNICÍPIOS & $\mathbf{2 0 0 2}$ & $\mathbf{2 0 0 3}$ & $\mathbf{2 0 0 4}$ & $\mathbf{2 0 0 5}$ & $\mathbf{2 0 0 6}$ & $\mathbf{2 0 0 7}$ \\
\hline Araruama & 9 & 7 & 7 & 8 & 8 & 6 \\
\hline Armação de Búzios & 122 & 133 & 142 & 153 & 154 & 146 \\
\hline Arraial do Cabo & 19 & 16 & 23 & 22 & 27 & 25 \\
\hline Cabo Frio & 51 & 53 & 47 & 45 & 48 & 52 \\
\hline Carapebus & 0 & 0 & 0 & 0 & 0 & 0 \\
\hline Cassimiro de Abreu & 7 & 5 & 4 & 4 & 9 & 9 \\
\hline Iguaba Grande & 2 & 1 & 3 & 3 & 5 & 3 \\
\hline Macaé & 27 & 36 & 36 & 39 & 44 & 46 \\
\hline Maricá & 3 & 2 & 4 & 6 & 5 & 4 \\
\hline Quissamã & 2 & 2 & 1 & 0 & 1 & 1 \\
\hline Rio das Ostras & 27 & 30 & 37 & 34 & 29 & 36 \\
\hline São Pedro da Aldeia & 10 & 14 & 14 & 11 & 8 & 8 \\
\hline Saquarema & 14 & 9 & 11 & 9 & 20 & 18 \\
\hline Total do PCS & $\mathbf{2 9 3}$ & $\mathbf{3 0 8}$ & $\mathbf{3 2 9}$ & $\mathbf{3 3 4}$ & $\mathbf{3 5 8}$ & $\mathbf{3 5 4}$ \\
\hline Total do Estado do RJ & 1.391 & 1.343 & 1.377 & 1.398 & 1.561 & 1.574 \\
\hline
\end{tabular}

Fonte: RAIS

* Nos anos de 2002, 2003, 2004 e 2005 a RAIS classifica como "estabelecimentos hoteleiros", enquanto nos anos 2006 e 2007 classifica como "hotéis e similares".

Dessa forma, a racionalidade espacial oriunda do próprio funcionamento do mercado também é identificada nas políticas governamentais. Na medida em que Armação de Búzios é selecionado pelos agentes de turismo atuantes na esfera pública federal para desempenhar o papel de indutor do turismo regional, isto vem reforçar as interações espaciais resultantes das forças do mercado, que, através da criação e reafirmação de centralidades, possibilitam condições mais vantajosas para a reprodução do capital, resultando em um espaço desigual e combinado.

\section{CONSIDERAÇÕES FINAIS}

A racionalidade do capital implica em uma racionalidade espacial, cuja lógica é oriunda dos agentes hegemônicos. No caso enfocado no presente estudo, tais agentes referem-se ao mercado e ao poder público, que desenvolvem ações e geram fixos materializados espacialmente de forma desigual, implicando em interações espaciais que canalizam a riqueza para algumas áreas em detrimento de outras. Procuramos mostrar que o funcionamento da atividade turística resulta em uma estrutura espacial desigual e combinada, de modo que as diferentes parcelas do espaço desempenham papéis distintos, porém, complementares.

Armação de Búzios se constitui o lugar central e de comando da atividade turística no interior do Polo Costa do Sol por concentrar os meios de produção da atividade e os demais municípios adjacentes dão sustentação à sua atividade econômica, uma vez que a infraestrutura e os atrativos turísticos encontrados nestes são necessários para a constituição do seu produto turístico.

No que se refere ao Programa de Regionalização de Turismo, estruturado através de polos, as perspectivas de êxito não são muito promissoras localmente haja vista o descompasso entre a proposição dessas políticas e os conflitos de interesses existentes entre os municípios, que, em seu conjunto, estão descontentes com as perspectivas da atividade turística no Polo. A omissão do poder público estadual em relação aos rumos do turismo fluminense vem comprometer ainda mais esse quadro de incertezas existente localmente. 
Neste sentido, um dos aspetos que merece ser melhor analisado é a forma como a disseminação de segundas residências tem afetado o desempenho da atividade econômica baseada no turismo. $\mathrm{O}$ aluguel das casas de veraneio causa forte impacto para os empresários do segmento hoteleiro, que se sentem prejudicados com o aluguel dessas casas para potenciais clientes. Essa preocupação é generalizada nos três municípios analisados na pesquisa. Além disso, a agressividade do mercado imobiliário provoca impactos ambientais, com a verticalização e a implantação de empreendimentos em locais inadequados, contribuindo para intensificar ainda mais os problemas já existentes, o que compromete o futuro turístico do Polo Costa do Sol.

\section{REFERÊNCIA BIBLIOGRÁFICA}

BENKO, G. A ciência regional. Oeiras: Celta Editora, 1999.

BOYER, M. História do turismo de massa. Bauru: EDUSC, 2003.

BRASIL, Programa de Regionalização do Turismo. Roteiros do Brasil, Ministério do Turismo, Brasília, 2004. FONSECA, M. et al. O significado do mar no turismo de Armação de Búzios. In: Faria, I. F (Coord.) Turismo. Sustentabilidade e novas territorialidades, EUAM. Manaus, 2001, pp. 123-136.

FONSECA, M. Espaço, políticas de turismo e competitividade, Natal: EDUFRN, 2004,

HARVEY, D. Espaços de esperança. São Paulo: Ed. Loyola, 2004, .

MÉNDEZ, R. Geografia econômica. A lógica espacial del capitalismo global. Barcelona: Editorial Ariel, 1997.

SÁNCHES, J. Espacio, economia y sociedad. Madri: Siglo Veintiuno Editores, 1991.

SANTOS, M. A natureza do espaço, 3 ed. São Paulo: , Hucitec, 1999.

SMITH, N. Desenvolvimento desigual. Rio de Janeiro: Bertrand, 1988.

SEPDET/TURISRIO. Plano diretor de turismo do Estado do Rio de Janeiro. Rio de Janeiro: 2001.

Trabalho enviado em janeiro de 2011

Trabalho aceito em abril de 2011 